\title{
Efficacy of A Loading Dose of IV Salbutamol in Children With Severe Acute Asthma Admitted to A PICU: A Randomized Controlled Trial
}

Shelley A Boeschoten ( $\sim$ s.boeschoten@erasmusmc.nl)

Erasmus MC Sophia Children Hospital: Erasmus MC Sophia https://orcid.org/0000-0001-9870-2067

Corinne M. Buysse

Erasmus MC Sophia Children Hospital: Erasmus MC Sophia

Brenda C. de Winter

Erasmus Medical Centre: Erasmus MC

Joost van Rosmalen

Erasmus Medical Centre: Erasmus MC

Johan C. de Jongste

Erasmus MC Sophia Children Hospital: Erasmus MC Sophia

Rogier C. de Jonge

Erasmus MC Sophia Children Hospital: Erasmus MC Sophia

\section{Sabien G. Heisterkamp}

Emma Childrens Hospital AMC: Emma Kinderziekenhuis Amsterdam UMC

Job B. van Woensel

Emma Childrens Hospital AMC: Emma Kinderziekenhuis Amsterdam UMC

Martin C. Kneyber

University Medical Centre Groningen Beatrix Childrens Hospital: Universitair Medisch Centrum

Groningen Beatrix Kinderziekenhuis

Annelies van Zwol

University Medical Center Nijmegen: Radboudumc

Annemie L. Boehmer

Spaarne Hospital: Spaarne Gasthuis

Matthijs de Hoog

Erasmus MC Sophia Children Hospital: Erasmus MC Sophia

Dutch collaborative PICU research network (SKIC)

Radboud University Nijmegen: Radboud Universiteit

Research Article

Keywords: Intensive care, status asthmaticus, severe acute asthma, therapy, children 
Posted Date: February 15th, 2021

DOI: https://doi.org/10.21203/rs.3.rs-176994/v1

License: (c) (i) This work is licensed under a Creative Commons Attribution 4.0 International License. Read Full License 


\section{Abstract}

The optimal dose regimen to start intravenous (IV) treatment in children with severe acute asthma (SAA), is still matter of debate. We assessed the efficacy of an additional salbutamol loading dose in children with SAA admitted to a pediatric intensive care unit (PICU). This multicenter, placebo-controlled randomized trial in the PICUs of four tertiary care children's hospitals included children (2-18 years) with SAA admitted between 2017-2019. Children were randomized to receive either a loading dose IV salbutamol (15 mcg/kg, max.750 mcg) or normal saline while on continuous salbutamol infusion. The primary outcome was asthma score (Qureshi) 1 hour after the intervention. Analysis of covariance models were used to evaluate sensitivity to change in asthma scores. Serum concentrations of salbutamol were obtained. Fifty-eight children were included (29 in the intervention group). Median baseline asthma score was 12 (IQR 10-13) in the intervention and 11 (9-12) in the control group $(p=0.032)$. The asthma score 1 hour after the intervention did not differ significantly between both groups $(p=0.508, \beta$-coefficient $=0.283)$. The median increase in salbutamol plasma levels 10 minutes after the intervention was $13 \mu \mathrm{g} / \mathrm{L}(5-24)$ in the intervention and $4 \mu \mathrm{g} / \mathrm{L}(0-7)$ in the control group $(p=0.001)$. Mixed model analyses showed a significant association between heart rate and asthma score, adjusted for salbutamol plasma levels.

Conclusion: We found no clinical benefit of a loading dose IV salbutamol, compared to normal saline in children with SAA admitted to the PICU. Clinicians should be less reluctant to increase the dose of salbutamol infusion, solely based on tachycardia.

\section{What Is Known:}

- Pediatric guidelines struggle with an evidence-based approach for SAA beyond the initial steps of oxygen suppletion, inhaled $\beta 2$-agonists, and systemic steroids

- Significant gaps remain in the knowledge on the efficacy of a salbutamol loading dose in SAA children admitted to the PICU

\section{What Is New?}

- No beneficial effect of a loading dose administered in the PICU added to continuous IV salbutamol on asthma score (Qureshi score 1 hour after the intervention)

- In our study tachycardia is due to respiratory distress and not related to serum concentration of salbutamol

\section{Introduction}

Severe acute asthma (SAA, status asthmaticus) is a severe or life-threatening asthma exacerbation that does not respond to oxygen suppletion, repetitive administration of inhaled $\beta 2$-agonists, and systemic steroids. Pediatric asthma guidelines struggle with an evidence-based approach for SAA beyond these 
initial steps [1-4]. During an SAA episode, effective delivery of inhaled drugs is unpredictable due to severe airway obstruction [5]. Therefore, intravenous (IV) salbutamol could be more effective.

Salbutamol is a racemic mixture of R-and S-isomers. The pharmacologic activity resides predominantly in the (R)-isomer, with little or no activity attributed to the (S)-isomer. The elimination of (R)-salbutamol is much more rapid than that of (S)-salbutamol, which leads to relatively higher plasma concentrations of (S)-salbutamol. There are concerns that particularly high exposure to S-salbutamol may have negative effects [6]. However, very little is known about the pharmacokinetics (PK) and pharmacodynamics (PD) of IV salbutamol in children and the rationale behind current dosing strategies. Following current international guidelines $[5,7,8]$, children receive much higher doses of continuous IV salbutamol per kilogram of weight than adults. A study by Starkey et al. [9] summarized current evidence and gaps in knowledge and concluded that the PK-PD of IV salbutamol in children is probably similar, but data are limited. A previous pilot study [6] on the PK of IV salbutamol in children has yielded a model of IV R- and S-salbutamol that described the data well and showed that in children a loading dose should be considered. This model can be used to evaluate PK-PD relationship of IV salbutamol in children, and the effectiveness and tolerability of (a loading dose) IV salbutamol.

Studies using a single-dose IV salbutamol in children admitted to the emergency department show that a loading dose has the potential to shorten the duration of asthma attacks and reduce overall requirements for inhaled salbutamol maintenance [10-12]. However, significant gaps remain in our current knowledge, including the efficacy of a salbutamol loading dose in children admitted to a pediatric intensive care unit (PICU)[13]. Previous studies showed no serious toxicity, but data are limited.

Since the number of children requiring PICU admission increased markedly in the last decade [14-17], together with the high costs of PICU admissions, bed availability and the risk of posttraumatic stress disorder after PICU admission in children and their parents [18-20], it is important to avoid PICU admission, and to keep any PICU stay as short as possible. Our primary objective was to assess the efficacy of a loading dose IV salbutamol in children with SAA admitted to a PICU. We hypothesized that a loading dose of IV salbutamol reduces the time to recovery. Secondary end points included the maximum rate and duration of infusion of IV salbutamol, total (cumulative) dose of IV salbutamol, length of PICU stay, need for other medication, need for (non-) invasive mechanical ventilation, the frequency of side effects, and serum concentrations of salbutamol. Since the limiting factor in increasing the dose of salbutamol is often tachycardia, although the tachycardia might be a consequence of respiratory distress, secondary end points included the association between salbutamol plasma levels and asthma score and the heart rate.

\section{Materials And Methods}

We prospectively identified children aged 2-18 years with SAA admitted to 4 of the 7 Dutch PICUs. All children admitted for SAA (April 2017-June 2019) with the need for IV salbutamol were eligible. According to current Dutch national guidelines [21], children require PICU admission once IV salbutamol is 
administered, regardless of the dosage. The effect of SAA treatment was determined by using the asthma score developed by Qureshi [Figure 1] [22]. The main study endpoint was a difference in asthma score of $\geq 2$ points between the intervention and control group, 1 hour after receiving an IV salbutamol loading dose. Asthma scores were assessed prior to administration of the study medication and 10 minutes, 1, 3, 6,12 and 24 hours after.

Blocked randomization with randomly selected block sizes was used, blocks were stratified by center. Study vials contained either salbutamol $(500 \mathrm{mcg} / \mathrm{ml})$ or placebo (sodium chloride $0.9 \%$ ). The medication bolus $(15 \mathrm{mcg} / \mathrm{kg}$ salbutamol with a maximum of $750 \mathrm{mcg}$ ) or placebo bolus was prepared according to the manufacturer's instructions. The study medication was administered IV over a period of 10 minutes. In both groups continuous infusion of salbutamol was started at the same time or continued in children who already received salbutamol IV. The loading dose of $15 \mathrm{mcg} / \mathrm{kg}$ was based on international guidelines $[5,7]$ and a previous pilot study into the PK of IV salbutamol in children [6].

Blood samples to determine salbutamol serum concentrations were obtained just before administration of the study medication, and 10 minutes, 1 hour and 24 hours (or prior to discharge) after.

The Research Ethics Committee of the Erasmus Medical Center Rotterdam (MEC 2016-402) approved the study and allowed either a priori or deferred informed consent.

See the online supplement for details on exclusion criteria, the asthma score, randomization procedure, study medication, blood samples, deferred consent, and the power analysis.

\section{Analyses}

Data were presented as mean and standard deviation (SD) or median and interquartile range (IQR) if appropriate. Differences between groups were analyzed using t-tests for normally distributed variables, Mann-Whitney tests for continuous variables that were not normally distributed, and chi-square or Fisher's exact tests were used to assess categorical variables. The linear-by-linear association chi-square test was used for ordinal categories. Analysis of covariance (ANCOVA) models were used to evaluate sensitivity to change in asthma scores after 1 and 6 hours after the study medication, controlling for center, baseline asthma score (before start study medication), and duration of IV salbutamol prior to study medication. Linear mixed model analyses were performed for the association between salbutamol plasma levels and asthma score and the heart rate, corrected for age. Statistical analyses were carried out in SPSS version 25 (Chicago,IL,USA) and Jamovi version 1.2 (the Jamovi Project, 2020, https://www.jamovi.org), and a two-sided significance level of 0.05 was used.

\section{Results}

Fifty eight children were included into the study [Figure 2]. Baseline characteristics are shown in Table 1. The median age was significantly lower in the intervention group ( 5 years vs 8 years, $p=0.03$ ). Asthma treatment levels before admission were comparable between both groups. 


\section{Primary outcome}

The median time between start of IV salbutamol infusion and administration of study medication was 154 minutes (IQR 124-187) in the intervention group and 108 minutes (IQR 75-158) in the control group $(p=0.04)$, with a median dose of IV salbutamol at baseline of $0.5 \mathrm{mcg} / \mathrm{kg} / \mathrm{min}$ (IQR $0.3-0.9)$ in the intervention group and $0.7 \mathrm{mcg} / \mathrm{kg} / \mathrm{min}$ (IQR 0.3-1.3) in the control group ( $p=0.48)$. The baseline asthma score (at start of study medication) in the intervention group was significantly higher (Table 2, Figure 3). After correction for baseline asthma score, center, and duration of continuous infusion of IV salbutamol, there were no statistically significant differences between both groups in asthma score 1 and 6 hours after the study medication (Table 3). Adjusting for age would lead to an effect of 0.44 with a $95 \% \mathrm{Cl}$ of $-0.46 / 1.34$ and a p-value of 0.33 .

\section{Secondary outcomes}

The difference in increase of salbutamol plasma levels from before the loading dose to 10 minutes after the loading dose was significant higher in the intervention group (Table 2). One hour after the loading dose there was no significant difference in salbutamol plasma levels between both groups.

Adjunct therapies and respiratory support were similar between both groups (Table 4). Hypotension (arterial blood pressure if available), was defined to be less than the 5th percentile of the systolic blood pressure [23], and was documented in 15 patients: 11 in the control group, and 4 in the intervention group $(p=0.077)$. None required inotropic support. One patient in the placebo group suffered from cardiac arrhythmia. The patient recovered without complications after discontinuing the IV salbutamol. In the intervention group 29 patients developed hyperglycaemia ( $>8 \mathrm{mmol} / \mathrm{L}$ ), compared with 27 patients in the control group $(p=0.150)$. None of the patients were treated with insulin.

Tachycardia was present in all but one patient during PICU admission. Mixed model analyses showed no significant association of plasma levels ( $R$ and $S$-salbutamol) and heart rate (crude $\beta$-coefficient 0.008 (95\%-Cl -0.010-0.027, $\mathrm{p}=0.375$ ). We did find a significant association of asthma score (work of breathing) and the heart rate (crude $\beta$-coefficient $2.710(95 \%-\mathrm{Cl} 1.780-3.630, p<0.001)$. Multivariable analyses with asthma score, plasma levels and age in the model did not effect this association: $\beta$-coefficient 2.719 $(95 \%-C l 1.813-3.623, p<0.001)$.

\section{Discussion}

In this randomized, multicentre, placebo-controlled trial no benefit was found of a loading dose IV salbutamol versus normal saline in children admitted to a PICU with SAA (majority already on IV salbutamol infusion), with regard to clinical asthma score, co-medication, respiratory support, and PICU length of stay (LOS). Neither were there side effects. We found an association between heart rate and asthma score, whilst no association was found between heart rate and salbutamol plasma levels, suggesting that tachycardia in SAA children is mainly caused by respiratory distress, not dose of salbutamol IV. 
Our findings are only partly consistent with previous studies. Single center randomized studies done in Australia (1994-1995, 1997-1998) showed shorter recovery time (e.g. cessation of inhaled medication), which resulted in earlier hospital discharge, in SAA children who received a bolus of IV salbutamol (15 $\mathrm{mcg} / \mathrm{kg}$ in 10 minutes), whereas no side effects were reported. However the results of these 2 studies cannot be compared to our present study. The setting was the emergency department (ED) and a loading dose salbutamol was not followed by or added to continuous salbutamol infusion $[10,11]$.

In 2007 Bogie performed a randomized, double blind, placebo-controlled trial on children with SAA presenting to an ED. Patients were randomized to receive either IV terbutaline (a loading dose followed by continuous infusion) or IV normal saline while on continuous high-dose nebulized albuterol. Outcome measures revealed a trend toward improvement in the terbutaline group [12]. In the present study we looked at the efficacy of a loading dose salbutamol while already on continuous infusion with salbutamol, in a PICU setting. We found no clinical benefit of an additional loading dose salbutamol in this population.

The efficacy of IV salbutamol was suggested in 1984 by Bohn et al, showing a decrease of PaCO2 in 11 of 16 SAA patients after a loading dose of $10 \mathrm{mcg} / \mathrm{kg}$ followed by continuous infusion of salbutamol [24]. This study is not comparable with the present study (e.g. different loading dose and outcome variable). None of these 4 studies described PK data [10-12, 24].

How can our findings, e.g. lack of efficacy of a loading dose IV salbutamol, be explained?

The pharmacologic activity of salbutamol resides predominantly in the (R)-isomer, with little or no activity, and concerns about adverse reactions, attributed to the (S)-isomer [6, 25]. Based on a previous population PK model of IV R- and S-salbutamol in SAA children, a loading dose seemed valid to reach higher initial Rsalbutamol concentrations with a possible therapeutic advantage [6].

All of our patients received nebulized salbutamol before IV. Furthermore, the majority of our children were already on IV salbutamol infusion (median dose at baseline of $0.5 \mathrm{mcg} / \mathrm{kg} / \mathrm{min}$ ) before inclusion. Although a salbutamol loading dose results in significant higher plasma levels 10 minutes after administration of the loading dose, this effect did not remain significant after 1 hour. Treatment with IV salbutamol resulted in high inter-individual differences in plasma salbutamol levels, with no clear correlation with pharmacodynamic parameters (e.g. asthma score and heart rate). Better knowledge of the pharmacokinetics of both R- and S-salbutamol is important to find the optimal dose for bronchodilation without adverse reactions.

Our study does not exclude a possible benefit of a loading dose of IV salbutamol in children with severe or near-fatal SAA in a pre-hospital setting or ED with very low baseline concentration salbutamol, as previously illustrated in a case report [26].

In SAA treatment, the goal of salbutamol as a selective $\beta 2$-adrenoreceptor agonist with potent smooth muscle relaxant properties, is bronchodilation. Could it be that inflammation or mucus plugging are more 
predominant in the cause of severe airflow obstruction in SAA? The pathophysiology or "clinical phenotype" of SAA children should be better understood.

IV salbutamol is more likely than inhaled salbutamol to produce systemic adverse reactions related to interaction with non-airway $\beta 1$ receptors, such as tachycardia and dysrhythmias. However, data on toxicity related to dose or serum concentrations are scarce. In a recent review on SAA in children, the limiting factor in increasing the dose of salbutamol is tachycardia. Also an NHS clinical guideline recommends to reduce the infusion rate of salbutamol in case of tachycardia. In the present study, there was no association between heart rate and serum salbutamol concentration, implicating that tachycardia was mainly caused by severity of respiratory distress, not by the dose of salbutamol. The PK-PD data could implicate that clinicians at the ED or PICU should titrate the dose of continuous salbutamol infusion on the severity of respiratory distress (including heart rate), taking into account that tachycardia after initiation of salbutamol inhalation or infusion was not found to be a side effect of SAA treatment in our study.

\section{Limitations/strengths}

Strengths of the present study include the randomized placebo-controlled design, the PK-PD analysis for (side)effects and the participation of the majority of Dutch PICU's.

There are some limitations as well. First as to the design of the study, most children received continuous infusion with salbutamol for more than 1 hour before start of study medication. Unfortunately, it was unfeasible to administer a blinded loading dose of IV salbutamol in regional hospitals (before the continuous infusion of IV salbutamol) as part of a research project. Second, the asthma score by Qureshi is a subjective description for determining asthma severity and change in clinical condition. The asthma score is widely used in studies regarding SAA. To our knowledge there have never been subsequent studies validating this score for different populations, and the precise characteristics of this score have not been determined; the original article mentions an interrater reliability of $80 \%$. It may therefore be that this score could be improved to detect clinical improvement in studies like the present one. However, since also co-medication, respiratory support and PICU LOS did not differ between both groups, it is unlikely that the asthma score was inappropriate.

\section{Conclusion}

In this multicenter, placebo-controlled randomized trial we found no beneficial effect of a loading dose IV salbutamol in SAA children admitted to a PICU (majority already on IV salbutamol infusion) with regard to clinical asthma score, co-medication, respiratory support and PICU LOS. Nor were there side effects. Tachycardia is related to dyspnea and not to salbutamol dosing. Therefore, clinicians should be less reluctant to increase the dose of IV salbutamol infusion, solely based on tachycardia.

Future studies should focus on the efficacy of a loading dose IV salbutamol in the ED, before or simultaneous with the start of continuous salbutamol infusion, with the ultimate goal of preventing 
further deterioration of respiratory distress (and PICU admission). Finally, a validated asthma score is needed to study the efficacy of different interventions in the context of ED and PICU care.

\section{Abbreviations}

ANCOVA Analysis of covariance

ED Emergency department

IVIntravenous

$I Q R$ Interquartile range

LOS Length of stay

PD Pharmacodynamics

PICU Pediatric intensive care unit

PKPharmacokinetics

SAA Severe acute asthma

SD Standard deviation

\section{Declarations}

Funding: This study was financially supported by the Dutch Foundation for Asthma Prevention (Stichting Astma Bestrijding) and Ammodo (Institute of Art and Science).

Conflict of Interest Statement: The authors have no conflicts of interest relevant to this article to disclose.

Availability of data and material: The authors confirm that the data supporting the findings of this study are available within the article and its supplementary materials.

Code availability: SPSS version 25 (Chicago,IL,USA) and Jamovi version 1.2 (the Jamovi Project, 2020, https://www.jamovi.org)

Authors' contribution: $\mathrm{CB}, \mathrm{BdW}, \mathrm{JdJ}, \mathrm{JvR}, \mathrm{AB}, \mathrm{RdJ}, \mathrm{MK}, \mathrm{SH}, \mathrm{JW}, \mathrm{AZ}, \mathrm{MdH}$ and SB conceptualized and designed the study, and reviewed and revised each draft of the manuscript. $\mathrm{CB}, \mathrm{MdH}, \mathrm{MK}, \mathrm{SH}, \mathrm{AZ}$, JW and SB collected data. SB, RdJ and JvR performed analysis. SB drafted the initial manuscript. All authors read and approved the final manuscript.

Ethics approval: The Research Ethics Committee of the Erasmus Medical Center Rotterdam (MEC 2016402) approved the study and allowed either a priori or deferred informed consent. 
Trial register: clinicaltrials.gov (NCT03493503)

Acknowledgements: Research consortium SKIC members (Dutch Collaborative PICU Research Network): Amsterdam University Medical Centers, Amsterdam, The Netherlands: Eric Haarman and Berber Kapitein; Wilhelmina Children's Hospital/University Medical Center Utrecht, Utrecht, The Netherlands: Roelie Wösten-van Asperen; University Medical Center Nijmegen, Nijmegen, The Netherlands: Joris Lemson; Maastricht University Medical Center, Maastricht, The Netherlands: Dick van Waardenburg; Leiden University Medical Center, Leiden, The Netherlands: Heleen Bunker and Carole Brouwer

\section{References}

1. Wong J, Agus MS, Graham DA, et al: A Critical Asthma Standardized Clinical and Management Plan Reduces Duration of Critical Asthma Therapy. Hosp Pediatr 2017; 7: 79-87

2. Rehder KJ: Adjunct Therapies for Refractory Status Asthmaticus in Children. Respir Care 2017; 62: 849-865

3. Newth CJ, Meert KL, Clark AE, et al: Fatal and near-fatal asthma in children: the critical care perspective. J Pediatr 2012; 161: 214-221 e213

4. Boeschoten S, de Hoog M, Kneyber M, et al: Current practices in children with severe acute asthma across European PICUs: an ESPNIC survey. Eur J Pediatr 2019

5. BTS/SIGN British guideline on the management of asthma. Available at: https://www.britthoracic.org.uk/quality-improvement/guidelines/asthma/. Accessed July 2019

6. Vet NJ, de Winter BCM, Koninckx M, et al: Population Pharmacokinetics of Intravenous Salbutamol in Children with Refractory Status Asthmaticus. Clin Pharmacokinet 2019

7. The Australian Asthma Handbook. Available at: https://www.asthmahandbook.org.au/acuteasthma/clinical/add-on-treatment. Accessed September 2020

8. British National Formulary for Children (BNFc).

9. Starkey ES, Mulla H, Sammons HM, et al: Intravenous salbutamol for childhood asthma: evidencebased medicine? Arch Dis Child 2014; 99: 873-877

10. Browne GJ, Penna AS, Phung $X$, et al: Randomised trial of intravenous salbutamol in early management of acute severe asthma in children. Lancet 1997; 349: 301-305

11. Browne GJ, Trieu L, Van Asperen P: Randomized, double-blind, placebo-controlled trial of intravenous salbutamol and nebulized ipratropium bromide in early management of severe acute asthma in children presenting to an emergency department. Crit Care Med 2002; 30: 448-453

12. Bogie AL, Towne D, Luckett PM, et al: Comparison of intravenous terbutaline versus normal saline in pediatric patients on continuous high-dose nebulized albuterol for status asthmaticus. Pediatr Emerg Care 2007; 23: 355-361

13. Travers AH, Milan SJ, Jones AP, et al: Addition of intravenous beta(2)-agonists to inhaled beta(2)agonists for acute asthma. Cochrane Database Syst Rev 2012; 12: CD010179 
14. Tse SM, Samson C: Time to Asthma-Related Readmission in Children Admitted to the ICU for Asthma. Pediatr Crit Care Med 2017; 18: 1099-1105

15. Hartman ME, Linde-Zwirble WT, Angus DC, et al: Trends in admissions for pediatric status asthmaticus in New Jersey over a 15-year period. Pediatrics 2010; 126: e904-911

16. Chiang BL, Hsieh CT, Wang LC, et al: Clinical course and outcome of children with status asthmaticus treated in a pediatric intensive care unit: a 15-year review. J Microbiol Immunol Infect 2009; 42: 488493

17. Boeschoten SA, Buysse CMP, Merkus P, et al: Children with severe acute asthma admitted to Dutch PICUs: A changing landscape. Pediatr Pulmonol 2018; 53: 857-865

18. Boeschoten SA, Dulfer K, Boehmer ALM, et al: Quality of life and psychosocial outcomes in children with severe acute asthma and their parents. Pediatr Pulmonol 2020

19. Bronner MB, Knoester H, Bos AP, et al: Follow-up after paediatric intensive care treatment: parental posttraumatic stress. Acta Paediatr 2008; 97: 181-186

20. Bronner MB, Peek N, Knoester $\mathrm{H}$, et al: Course and predictors of posttraumatic stress disorder in parents after pediatric intensive care treatment of their child. J Pediatr Psychol 2010;35: 966-974

21. Dutch guideline for the management of acute asthma in children. Available at: https://www.nvk.nl/Portals/0/richtlijnen/acuut\%20astma/Methodenacuutastma.pdf. Accessed 2012

22. Qureshi F, Pestian J, Davis P, et al: Effect of nebulized ipratropium on the hospitalization rates of children with asthma. N Engl J Med 1998; 339: 1030-1035

23. Haque IU, Zaritsky AL. Analysis of the evidence for the lower limit of systolic and mean arterial pressure in children. Pediatr Crit Care Med 2007; 8: 138-144

24. Bohn D, Kalloghlian A, Jenkins J, et al: Intravenous salbutamol in the treatment of status asthmaticus in children. Crit Care Med 1984; 12: 892-896

25. Handley D. The asthma-like pharmacology and toxicology of (S)-isomers of beta agonists. J Allergy Clin Immuno/ 1999; 104: S69-76

26. Boeschoten SA, van der Crabben RS, Boehmer ALM, et al: A Loading Dose of IV Salbutamol in an Adolescent with Severe Acute Asthma and Cardiac Arrest. Case Rep Pediatr 2019: 5057390

\section{Tables}

\section{TABLE 1 - Baseline characteristics}




\begin{tabular}{|c|c|c|c|}
\hline & $\begin{array}{l}\text { Intervention group } \\
(\mathrm{n}=29)\end{array}$ & $\begin{array}{l}\text { Control group } \\
(n=29)\end{array}$ & $\begin{array}{l}P \\
\text { value }\end{array}$ \\
\hline Age in years & $5(3-9)$ & $8(5-13)$ & .03 \\
\hline $2-4$ years & $12(41)$ & $6(21)$ & .09 \\
\hline $5-18$ years & $17(59)$ & $23(79)$ & \\
\hline Male gender & $22(76)$ & $19(66)$ & .39 \\
\hline Caucasian & $12(43)$ & $15(54)$ & .42 \\
\hline $\begin{array}{l}\text { Diagnosed with asthma prior to } \\
\text { admission }\end{array}$ & $24(83)$ & $23(79)$ & .74 \\
\hline $\begin{array}{l}\text { Medication step prior to admission } \\
\text { (GINA) }^{\text {a }}\end{array}$ & & & .58 \\
\hline No medication & $3(10)$ & $6(21)$ & \\
\hline Step 1 & $12(41)$ & $7(24)$ & \\
\hline Step 2 & $0(-)$ & $2(7)$ & \\
\hline Step 3 & $7(24)$ & $11(38)$ & \\
\hline Step 4 & $6(21)$ & $3(10)$ & \\
\hline Step 5 & $1(3)$ & $0(-)$ & \\
\hline \multicolumn{4}{|l|}{ Prior hospital admissions } \\
\hline Non-PICU admission & $16(55)$ & $17(59)$ & .79 \\
\hline PICU admission & $5(17)$ & $10(35)$ & .13 \\
\hline Admission previous year & $10(35)$ & $9(31)$ & .78 \\
\hline
\end{tabular}

Data are presented in median (IQR) or number $(\%)^{a}$ children with a diagnosis of asthma prior to admission

TABLE 2 - PK/PD data 


\begin{tabular}{|c|c|c|c|}
\hline & $\begin{array}{l}\text { Intervention } \\
\text { group }(n=29)\end{array}$ & $\begin{array}{l}\text { Control } \\
\text { group }(n=29)\end{array}$ & $\begin{array}{l}\mathrm{P} \text { - } \\
\text { value }\end{array}$ \\
\hline Asthma score at PICU admission & $12(11-13)$ & $11(10-12)$ & .04 \\
\hline Baseline asthma score ${ }^{a}$ & $12(10-13)$ & $11(9-12)$ & .03 \\
\hline Asthma score 1 hour after intervention & $11(9-12)$ & $10(8-11)$ & .06 \\
\hline Asthma score 6 hours after intervention & $9(8-11)$ & $8(7-10)$ & .23 \\
\hline$\Delta$ Asthma score at baseline and 1 hour after intervention & $-0.8(1.6)$ & $-0.8(1.4)$ & .89 \\
\hline $\begin{array}{l}\Delta \text { Asthma score at baseline and } 6 \text { hours after } \\
\text { intervention }\end{array}$ & $-2.0(2.3)$ & $-1.7(1.7)$ & .60 \\
\hline Maximum rate of salbutamol IV in $\mathrm{mcg} / \mathrm{kg} / \mathrm{min}$ & $2(0.1-10)$ & $1.5(0.3-6.0)$ & 69 \\
\hline Total cumulative dose of IV salbutamol in $\mathrm{mcg} / \mathrm{kg}$ & $\begin{array}{l}3180(751- \\
6636)\end{array}$ & $\begin{array}{l}1671(706- \\
5873)\end{array}$ & .54 \\
\hline Duration of salbutamol IV in hours & $43(26-72)$ & $31(18-43)$ & .23 \\
\hline $\begin{array}{l}\text { R-salbutamol baseline plasma level in } \mu \mathrm{g} / \mathrm{L} \text {, median } \\
\text { (range) }^{\mathrm{b}}\end{array}$ & $37(7-191)$ & $51(6-219)$ & .21 \\
\hline $\begin{array}{l}\text { S-salbutamol baseline plasma level in } \mu \mathrm{g} / \mathrm{L} \text {, median } \\
\text { (range) }{ }^{\mathrm{b}}\end{array}$ & $65(16-318)$ & $79(18-347)$ & .40 \\
\hline $\begin{array}{l}\Delta \text { R-salbutamol plasma level before and } 10 \mathrm{~min} \text { after } \\
\text { intervention }\end{array}$ & $13(5-24)$ & $4(0-7)$ & .001 \\
\hline $\begin{array}{l}\Delta \text { R-salbutamol plasma level before and } 1 \text { hour after } \\
\text { intervention }\end{array}$ & $16(3-40)$ & $11(3-29)$ & .51 \\
\hline $\begin{array}{l}\Delta \text { S-salbutamol plasma level before and } 10 \mathrm{~min} \text { after } \\
\text { intervention }\end{array}$ & $18(10-28)$ & $4(0-9)$ & $<.001$ \\
\hline $\begin{array}{l}\Delta \text { S-salbutamol plasma level before and } 1 \text { hour after } \\
\text { intervention }\end{array}$ & $26(6-48)$ & $12(1-33)$ & .17 \\
\hline
\end{tabular}

Data are in median (IQR), mean (SD), $\Delta=$ difference, $^{\text {a }}$ At start of the intervention, ${ }^{\text {b }}$ Before administration of the study medication

\section{TABLE 3 - ANCOVA analysis}




\begin{tabular}{|c|c|c|c|c|c|c|}
\hline \multirow{2}{*}{$\begin{array}{l}\text { Dependent var. } \\
\text { Parameter }\end{array}$} & \multirow{2}{*}{$\begin{array}{l}\text { hour } \\
\beta \\
\text { coefficient } \\
\text { a }\end{array}$} & \multicolumn{2}{|c|}{ Asthma score at 1} & \multirow{2}{*}{$\begin{array}{l}\text { hours } \\
\beta \\
\text { coefficient } \\
\text { a }\end{array}$} & \multicolumn{2}{|c|}{ Asthma score at 6} \\
\hline & & $95 \% \mathrm{Cl}$ & $\begin{array}{l}\mathrm{p}- \\
\text { value }\end{array}$ & & $95 \% \mathrm{Cl}$ & $\begin{array}{l}\mathrm{p}- \\
\text { value }\end{array}$ \\
\hline Intercept & 1.453 & $-2.752 / 5.659$ & .490 & 2.137 & $-3.282 / 7.555$ & .432 \\
\hline [Centre 1] & -.043 & $-3.050 / 2.964$ & .977 & 2.425 & $-1.459 / 6.309$ & .215 \\
\hline [Centre 2] & -.072 & $-3.127 / 2.983$ & .962 & 1.098 & $-2.848 / 5.045$ & .578 \\
\hline [Centre 3] & 1.533 & $-1.910 / 4.976$ & .375 & 2.690 & $-1.750 / 7.130$ & .229 \\
\hline [Centre 4] & Reference & . & . & Reference & . & . \\
\hline $\begin{array}{l}\text { [Randomisation = } \\
\text { Loading dose] }\end{array}$ & .283 & $-.570 / 1.136$ & .508 & .237 & $-.876 / 1.350$ & .670 \\
\hline $\begin{array}{l}\text { [Randomisation = } \\
\text { Placebo] }\end{array}$ & Reference & . & . & Reference & . & . \\
\hline Baseline asthma score & .757 & $.500 / 1.015$ & .000 & .476 & $.144 / .809$ & .006 \\
\hline $\begin{array}{l}\text { Duration salbutamol } \\
\text { infusion before study } \\
\text { medication, in hours }\end{array}$ & .099 & $-.232 / .431$ & .550 & -.174 & $-.612 / .263$ & .426 \\
\hline
\end{tabular}

${ }^{a} \beta$ coefficients indicate how much a dependent variable changes per each unit variation of the independent variable, taking into account the effect of the other independent variables in the model. For categorical variables, $\beta$ coefficients represent the effect of moving from the reference category $(0)$ to another

TABLE 4 - Presentation and PICU management 


\begin{tabular}{|c|c|c|c|c|}
\hline \multirow[b]{2}{*}{$\mathrm{pH}$ at PICU admission, mean (SD) } & \multirow{2}{*}{$\begin{array}{l}\text { Intervention group } \\
(\mathrm{n}=29) \\
7.37(0.1)\end{array}$} & \multicolumn{2}{|c|}{$\begin{array}{l}\text { Control group } \\
(n=29)\end{array}$} & \multirow[t]{2}{*}{$\begin{array}{l}\mathrm{P} \text { - } \\
\text { value }\end{array}$} \\
\hline & & $\begin{array}{l}7.37 \\
(0.1)\end{array}$ & .956 & \\
\hline $\begin{array}{l}\mathrm{PCO}_{2} \text { at } \mathrm{PICU} \text { admission }(\mathrm{kPa}) \text {, mean } \\
(\mathrm{SD})\end{array}$ & $5.4(1.6)$ & $5.3(1.3)$ & .747 & \\
\hline Asthma severity score (Qureshi), n (\%) & & & .007 & \\
\hline Mild (5-7) & $0(-)$ & $1(3)$ & & \\
\hline Moderate (8-11) & $10(35)$ & $19(66)$ & & \\
\hline Severe (12-15) & $19(66)$ & $9(31)$ & & \\
\hline Adjunct therapies, n (\%) & & & .706 & \\
\hline Ketamine & $4(14)$ & $0(-)$ & & \\
\hline Sodium Bicarbonate & $1(3)$ & $1(3)$ & & \\
\hline Theophylline & $0(-)$ & $1(3)$ & & \\
\hline DNAse & $1(-)$ & $1(-)$ & & \\
\hline Maximal respiratory support, $\mathrm{n}(\%)$ & & & .753 & \\
\hline None & $0(-)$ & $1(3)$ & & \\
\hline Nasal cannula & $4(14)$ & $3(10)$ & & \\
\hline Non-rebreathing mask & $11(38)$ & $10(35)$ & & \\
\hline High-flow nasal cannula & $14(48)$ & $14(48)$ & & \\
\hline Non-invasive ventilation & $0(-)$ & $0(-)$ & & \\
\hline Invasive mechanical ventilation ${ }^{a}$ & $0(-)$ & $1(3)$ & & \\
\hline PICU length of stay in hours, mean (SD) & $58(28)$ & $55(36)$ & .696 & \\
\hline
\end{tabular}

a Invasive mechanical ventilation (IMV) after administration of the study medication, since IMV was an exclusion criteria

\section{Figures}




\section{Variable}

Respiratory rate

(breaths/min)

$2-3 \mathrm{yr}$

$4-5 \mathrm{yr}$

$6-12 \mathrm{yr}$

$>12 \mathrm{yr}$

Oxygen saturation (\%)

Auscultation

Retractions

Dyspnea

Asthma Scoring

1 point

1 point

\section{3 points}

$$
\begin{aligned}
& \leq 34 \\
& \leq 30 \\
& \leq 26 \\
& \leq 23
\end{aligned}
$$

$$
35-39
$$$$
\geq 40
$$

$31-35$

$27-30$

$24-27$

$>95$ with room air

Normal breathing or end-expiratory

wheezing

90 - 95 with room air

$<90$ with room air or supplemental oxygen

Expiratory wheezing Inspiratory and expiratory wheezing, diminished breaths sounds, or both

None or intercostal Intercostal and substernal

Speaks in sentences or coos and babbles
Speaks in partial sentences or utters short cries

\section{Severity of Asthma}

Mild Moderate Severe

Asthma score

Figure 1

The Asthma Score (by Qureshi) 


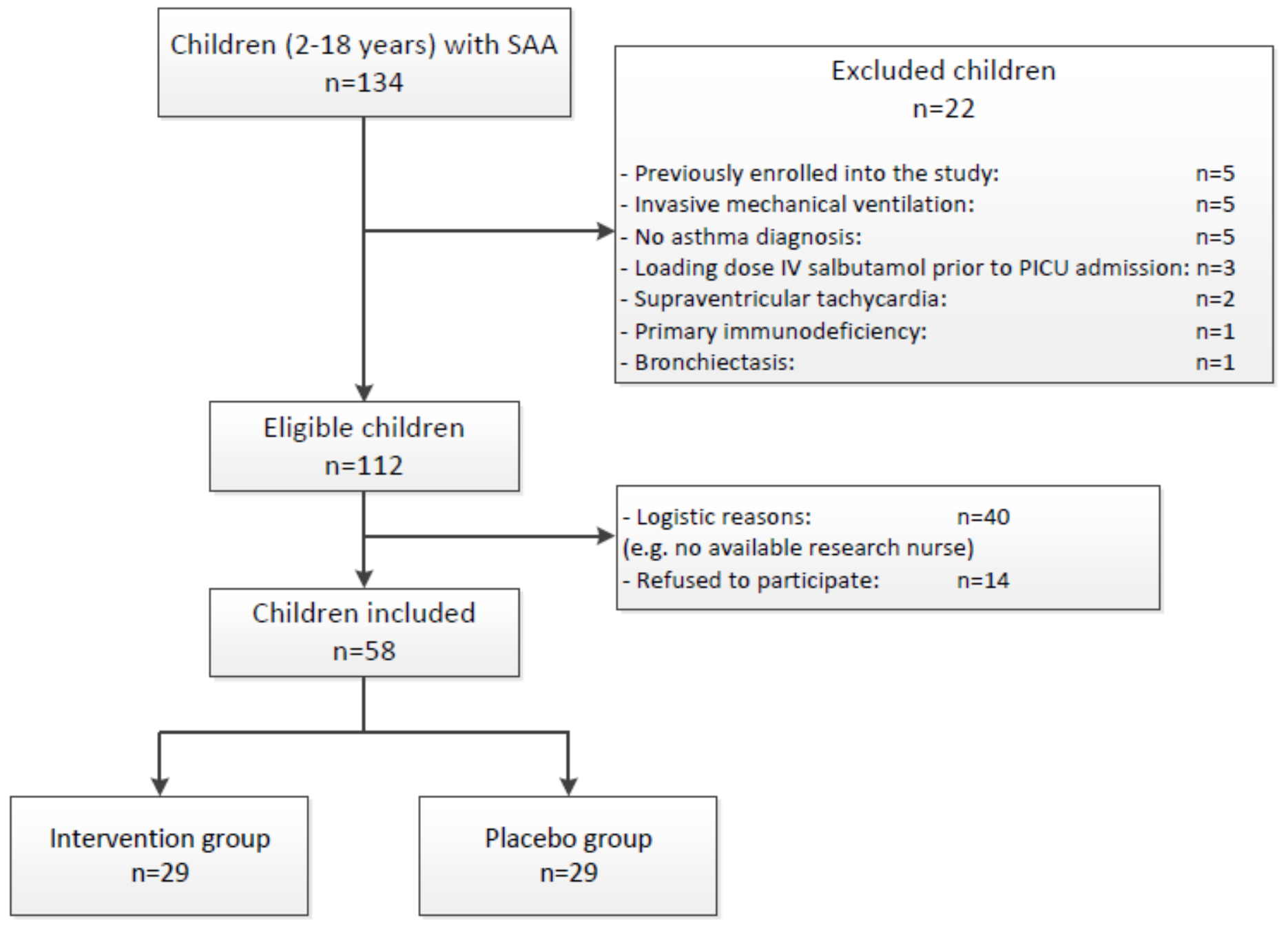

Figure 2

Flowchart Inclusion 


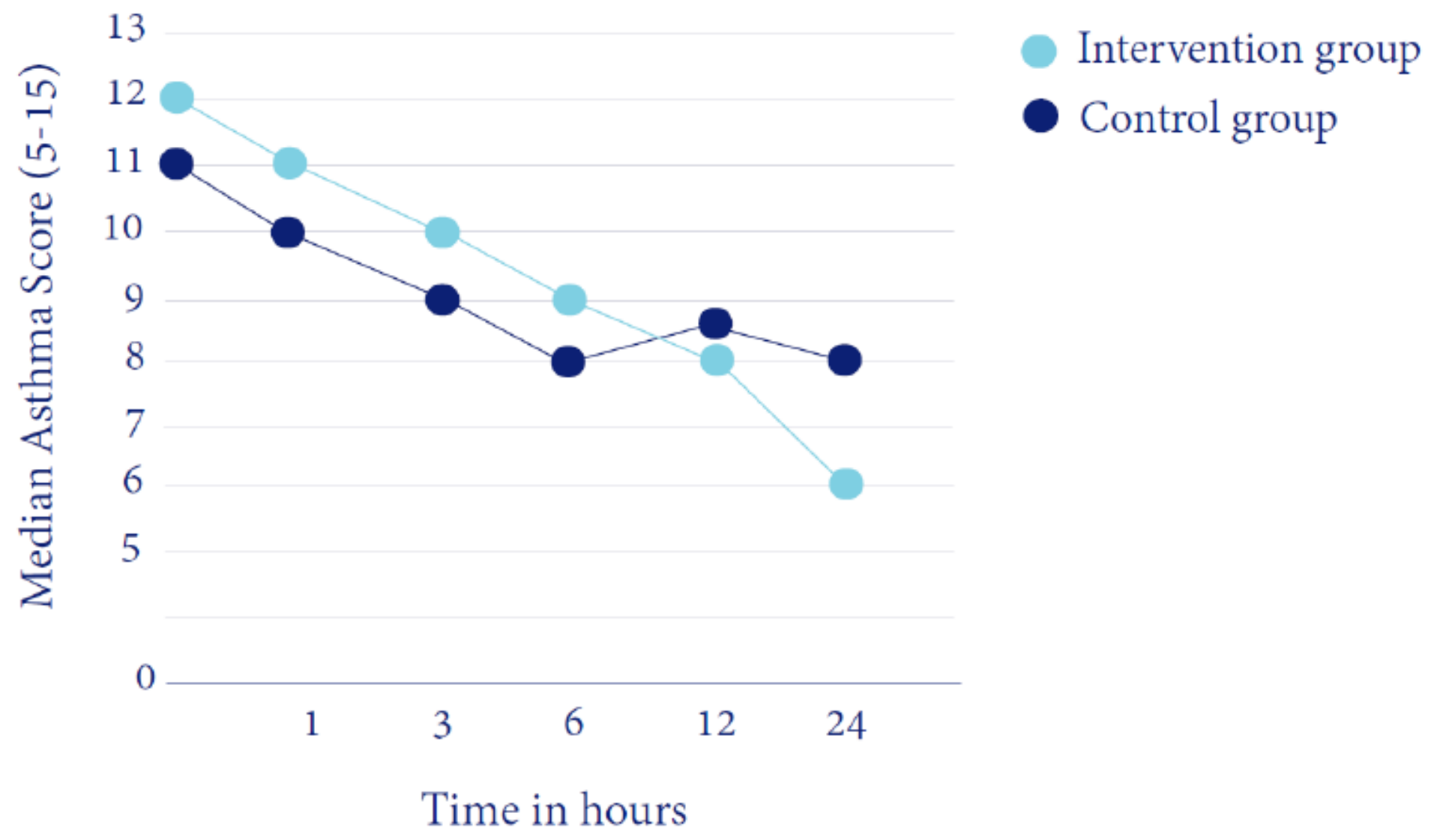

Figure 3

The median asthma score (Y-axis: median asthma score (5-15), X-axis: time in hours after PICU admission)

\section{Supplementary Files}

This is a list of supplementary files associated with this preprint. Click to download.

- OnlineDataSupplementEfficacyloadingdose.docx 